\title{
Impact of water quality on removal of carbamazepine in natural waters by TiON Photo-Catalytic thin film surfaces
}

\author{
Dror Avisar $^{\mathrm{a}^{*}}$, Inna Horovitz ${ }^{\mathrm{a}, \mathrm{b}}$, Luca Lozzi $^{\mathrm{c}}$, Fabrizio Ruggeri $^{\mathrm{c}}$, Mark Baker ${ }^{\mathrm{d}}$, Marie-Laure \\ Abel $^{\mathrm{d}}$, Hadas Mamane ${ }^{\mathrm{b}}$
}

\begin{abstract}
${ }^{a}$ The Hydro-Chemistry Laboratory, Faculty of Geography and the Environment, Tel Aviv University, Tel Aviv 69978, Israel

${ }^{\mathrm{b}}$ School of Mechanical Engineering, Faculty of Engineering, Tel Aviv University, Tel Aviv

69978, Israel

${ }^{c}$ Department of Physics, University of L'Aquila, Via Vetoio, I-67010 Coppito, L'Aquila, Italy

${ }^{\mathrm{d}}$ The Surface Analysis Laboratory, Faculty of Engineering and Physical Sciences, University of

Surrey, Guildford, Surrey GU2 7XH, UK

*Corresponding author e-mail: drorvi@post.tau.ac.il.
\end{abstract}

\begin{abstract}
Photocatalytic experiments on the pharmaceutical pollutant carbamazepine (CBZ) were conducted using sol-gel nitrogen-doped $\mathrm{TiO}_{2}$-coated glass slides under a solar simulator. CBZ was stable to photodegradation under direct solar irradiation. No CBZ sorption to the catalyst surface was observed, as further confirmed by surface characterization using X-ray photoelectron spectroscopic analysis of doped surfaces. When exposing the catalyst surface to natural organic matter (NOM), an excess amount of carbon was detected relative to controls, which is consistent with NOM remaining on the catalyst surface. The catalyst surface charge was negative at $\mathrm{pH}$ values from 4 to 10 and decreased with increasing $\mathrm{pH}$, correlated with enhanced $\mathrm{CBZ}$ removal with increasing medium $\mathrm{pH}$ in the range of 5 to 9 . A dissolved organic carbon concentration of 5 $\mathrm{mg} / \mathrm{L}$ resulted in $\sim 20 \%$ reduction in CBZ removal, probably due to competitive inhibition of the photocatalytic degradation of CBZ. At alkalinity values corresponding to $\mathrm{CaCO}_{3}$ addition at 100 $\mathrm{mg} / \mathrm{L}$, an over $40 \%$ decrease in CBZ removal was observed. A $35 \%$ reduction in CBZ occurred in the presence of surface water compared to complete suppression of the photocatalytic process in wastewater effluent.
\end{abstract}


Keywords: $\mathrm{N}$-doped $\mathrm{TiO}_{2}$; Photocatalytic activity; Carbamazepine; NOM; Water treatment

\section{Introduction}

The legal discharge of low concentrations of pharmaceutical residues from point and nonpoint sources to receiving waters [1] has resulted in some of these contaminants ending up in irrigation water, potentially leading to groundwater contamination $[2,3]$. In the European Union (EU) today, 3000 different substances are used in medicines such as painkillers, antibiotics, contraceptives, beta-blockers, lipid regulators, tranquilizers, and impotence drugs. Frequently used pharmaceuticals (the anti-epileptic carbamazepine-CBZ) and analgesic antiinflammatory drugs (ibuprofen, diclofenac, ketoprofen and naproxen) have been detected in lakes, rivers and wastewater-treatment plant effluents in Switzerland, at concentrations ranging between 5 and $3500 \mathrm{ng} / \mathrm{L}$ [4]. To meet the increasingly rigorous water-quality standards, advanced treatment technologies for water and wastewater treatment plants need to be developed and adopted.

In advanced oxidation processes (AOPs), pollutants are chemically oxidized by nonselective hydroxyl free radicals. The versatility of the AOPs is enhanced by the different ways in which hydroxyl radicals can be produced, facilitating compliance with the specific treatment requirements. Homogeneous UV- and ozone-based AOPs can produce hydroxyl radicals in the combinations $\mathrm{H}_{2} \mathrm{O}_{2} / \mathrm{UV}, \mathrm{O}_{3} / \mathrm{UV}, \mathrm{H}_{2} \mathrm{O}_{2} / \mathrm{O}_{3} / \mathrm{UV}, \mathrm{O}_{3} / \mathrm{H}_{2} \mathrm{O}_{2}$. Other methods, such as heterogeneous photocatalysis and homogeneous photo-Fenton, are based on the use of a wide-band gap semiconductor and addition of $\mathrm{H}_{2} \mathrm{O}_{2}$ to the dissolved iron salts, respectively, and irradiation with UV-visible light. 
The use of semiconductors in combination with sunlight irradiation (i.e. photocatalysis) for the treatment of water and wastewater has attracted growing attention and intense research interest in the last decade [5]. Semiconductors can be excited by light with higher energy than the band gap to generate energy-rich electron-hole pairs. The photogenerated holes and electrons can recombine or make their way to the catalyst surface, where they can react with and degrade adsorbed target pollutants or form reactive oxygen species (e.g. $\mathrm{OH} \bullet$ radicals). $\mathrm{TiO}_{2}$ is the most widely used photocatalyst, mainly due to its high efficiency, photochemical stability, nontoxic nature and low cost [6].

$\mathrm{TiO}_{2}$ has been widely applied to remove trace micropollutants (e.g. pharmaceuticals) from water [7-9] and wastewater effluent [10,11], and as a water disinfectant $[12,13]$. The main limitation of $\mathrm{TiO}_{2}$ is a relatively wide band gap, (3.02 eV for rutile, $3.2 \mathrm{eV}$ for anatase) [14], which results in about 5\% spectral overlap between its absorbance and sunlight emission $(\lambda<$ $\sim 390 \mathrm{~nm}$ ). Different attempts to overcome this drawback have made use of physical and chemical means such as morphological modifications to increase active surface area [15], use of other semiconductors such as $\mathrm{WO}_{3}$ or $\mathrm{ZnO}$, used with $\mathrm{TiO}_{2}$ or as independent catalysts $[16,17]$, and doping the $\mathrm{TiO}_{2}$ with different elements, such as nitrogen. Asahi et al. [18] were one of the first to describe $\mathrm{N}$-doped $\mathrm{TiO}_{2}$ materials. $\mathrm{N}$ doping showed effective $\mathrm{UV}$ and visible light activity.

CBZ is used for the treatment of seizure disorders, for the relief of neuralgia, and for a wide variety of mental disorders. This drug is the most frequently detected pharmaceutical in various water sources. Usually, CBZ is excreted with $<3 \%$ remaining in its unaltered form and flushed directly to the wastewater treatment plants (WWTPs) through the sewage system. Studies have determined that CBZ is persistent, with removal efficiencies by the WWTPs are being mostly 
below $10 \%$. In the classification scheme for pharmaceutical biodegradation, CBZ has the status of "no-removal" [19]. Clara et al. [20] and Kosjek et al. [21] reported that CBZ is resistant to biodegradation and shows almost no elimination during conventional wastewater treatment.

Photocatalytic efficiency is expected to be lower for natural water. This is due to the water's chemical composition, particularly the photoactive and inhibitor compounds present in different water bodies, which have a substantial impact on reaction pathways. Moreover, natural organic matter (NOM) and alkalinity are expected to be the main inhibitors of photocatalytic degradation of micropollutants as they may absorb photons and scavenge radicals, reducing the formation of more reactive oxidation species (e.g. $\mathrm{OH} \bullet$ ).

This paper addresses the effects of the interaction between water characteristics and the photocatalytic surface on the photodegradation of target organic pollutants. The main objectives of this study were to (a) examine the influence of NOM and water contaminants on the photocatalytic efficiency of a sol-gel $\mathrm{N}$-doped $\mathrm{TiO}_{2}$ surface on $\mathrm{CBZ}$, (b) characterize the streaming potential and hydrophobicity of the coated surface and their correlation to CBZ removal, and (c) determine the photocatalytic degradation of $\mathrm{CBZ}$ under various conditions $(\mathrm{pH}$, NOM, alkalinity) and water types (surface, ground and wastewater effluents).

\section{Materials and methods}

\subsection{Materials and reagents}

Carbamazepine (>99\% purity) was obtained from Sigma-Aldrich; LC-MS grade methanol and water were from Bio-Lab Ltd. (Jerusalem, Israel). HPLC-grade formic acid (Bio-Lab) was 
used to adjust $\mathrm{pH}$ during HPLC/MS analyses. All chemicals were used as obtained and CBZ stock solution was prepared by dissolving the compound in deionized (DI) water (Direct-Q3 UV System, Millipore, France) at a concentration of $50 \mathrm{mg} / \mathrm{L}$. Suwannee River NOM was obtained from the International Humic Substances Society (IHSS). $\mathrm{CaCO}_{3}$ was prepared from a stock solution of dissolved $\mathrm{NaHCO}_{3}$.

\subsection{Water types}

Groundwater samples were taken from a local site of the major carbonate aquifer in the eastern slopes of the Judea Mountain Ridge in central Israel. Natural surface water was sampled from Lake Kinneret (Sea of Galilee) located in northern Israel, and from part of the Israeli water network supply. Secondary and tertiary wastewater was sampled from the Dan Region Wastewater Treatment Plant (Shafdan), which is a complex inter-regional system that treats and reclaims municipal wastewater in high-density urban areas and industrial zones. The tertiary effluent was obtained after in-line granular filtration with ferric chloride.

\subsection{Preparation of $\mathrm{N}$-doped $\mathrm{TiO}_{2}$ coatings}

Precursor solutions for $\mathrm{N}$-doped $\mathrm{TiO}_{2}$ coatings were prepared with tetrabutylorthotitanate, isopropanol, ammonium hydroxide and triethanolamine [22]. Tetrabutylorthotitanate (25 $\mathrm{mL})$ and triethanolamine $(15 \mathrm{~mL})$ were dissolved in isopropanol $(32 \mathrm{~mL})$, together with ammonium hydroxide $(32 \%, 2.4 \mathrm{~mL})$. After stirring vigorously for $30 \mathrm{~min}$ at room temperature, the solution was ready for use. The substrates (standard microscope glass slide75 mm x $25 \mathrm{~mm}$ x $1.5 \mathrm{~mm}$ ) 
were carefully cleaned by ultrasonic treatment with acetone and air-dried. The N-doped $\mathrm{TiO}_{2}$ coatings were prepared by a dip-coating method, with a withdrawal speed of about $1 \mathrm{~mm} / \mathrm{s}$. To dry the samples, the coated substrates were left for $5 \mathrm{~min}$ at $100^{\circ} \mathrm{C}$ in the dip system before removing them. Then they were dried at $150^{\circ} \mathrm{C}$ for $12 \mathrm{~h}$ in air; the temperature was raised at $3^{\circ} \mathrm{C} / \mathrm{min}$ to $510^{\circ} \mathrm{C}$ and the samples were kept at this temperature for $1 \mathrm{~h}$ to allow the film to crystallize in anatase phase, as confirmed by X-ray diffraction measurements (data not shown).

\subsection{Experimental setup}

$\mathrm{N}$-doped $\mathrm{TiO}_{2}$ coatings were immersed in a $90 \mathrm{~mm}$ x $50 \mathrm{~mm}$ Pyrex glass plate containing 30 $\mathrm{mL}$ aqueous solution (DI water) containing CBZ (diluted from stock solution to an initial concentration of $\left.1 \mathrm{mg} / \mathrm{L}, 4.24 \times 10^{-6} \mathrm{M}\right)$. Unless otherwise indicated, experiments were carried out at neutral $\mathrm{pH}(7)$ adjusted using $1 \mathrm{mM}$ phosphate buffer saline (PBS) $\left(\mathrm{Na}_{2} \mathrm{HPO}_{4} / \mathrm{NaH}_{2} \mathrm{PO}_{4}\right)$. The examined solution was stirred for $60 \mathrm{~min}$ in the dark to ensure adsorption/desorption equilibrium of $\mathrm{CBZ}$ on the catalyst prior to its irradiation under a solar simulator for $90 \mathrm{~min}$. Samples of $0.25 \mathrm{~mL}$ were taken periodically and analyzed by HPLC to quantify the CBZ concentration. All experiments were performed in triplicate and relative standard deviations were less than $10 \%$. Specifically to determine the influence of $\mathrm{pH}$, PBS $(10 \mathrm{mM})$ was used in different ratios of $\mathrm{Na}_{2} \mathrm{HPO}_{4}$ to $\mathrm{NaH}_{2} \mathrm{PO}_{4}$. The photocatalytic efficiency was expressed as percent removal:

Removal $(\%)=\frac{C_{0}-C_{t}}{C_{0}} \times 100 \quad E q .(1)$

where $C_{0}$ is the initial pollutant concentration and $C_{t}$ is the pollutant concentration after $\mathrm{t}$ hours of irradiation $(\mathrm{mg} / \mathrm{L})$. Additional UV photolysis experiments were carried out in a bench-scale collimated beam apparatus using a $0.45-\mathrm{kW}$ polychromatic medium-pressure (MP) $\mathrm{Hg}$ vapor 
lamp (Ace-Hanovia lamp, Ace Glass Inc., Vineland, NJ). Absorption for each water sample as a function of wavelength was measured by a CARY 100Bio Spectrophotometer.

\subsection{Photocatalytic degradation experiments}

Solar irradiation experiments were carried out in a 150-W xenon arc lamp solar simulator (Sciencetech Inc., ON, Canada). The light beam was filtered with an air mass (AM) 1.5 Global filter that simulates the total (direct and diffuse) solar spectrum equivalent to natural sunlight at $48.2^{\circ}$ latitude at sea level. Irradiance was measured using a calibrated spectroradiometer (International Light, Model ILT 900R, MA, USA), placed in the same position as the irradiated solution. Fig. 1 shows the similarity between the spectra obtained from the solar simulator and natural sunlight. Total incident irradiance integrated between 280 and $950 \mathrm{~nm}$ was $500 \mathrm{~W} / \mathrm{m}^{2}$, including UVA irradiance of $21.5 \mathrm{~W} / \mathrm{m}^{2}$ and UVB irradiance of $0.9 \mathrm{~W} / \mathrm{m}^{2}$.

Fig. 1

\subsection{Chemical analysis}

CBZ was detected and quantified by HPLC Agilent 1100 (ACE-RP Phenyl column $2.1 \mathrm{~mm} \times$ $250 \mathrm{~mm}$ ) with a diode array detector. The flow rate was set to $0.5 \mathrm{~mL} / \mathrm{min}$ and the injected volume was $50 \mu \mathrm{L}$. The mobile phase consisted of water (A) and methanol (B), at $\mathrm{pH} 3$. The mobile phase eluent gradient started with $60 \%$ of eluent A, followed by a 2-min linear gradient 
to $10 \%$ eluent A, 4-min isocratic elution and a 2-min linear gradient back to $60 \%$ eluent A, maintained for 5 min to equilibration.

\subsection{Water analysis}

Alkalinity was determined by titration method using $\mathrm{HACH}$ digital titrator model 16900 (method 8203) [23], total hardness was determined by titration (method 8213) [23], and chloride was determined by titration (method 8206) [23]. Turbidity was measured using a HACH 2100Q portable turbidometer. The dissolved organic carbon (DOC) fraction was determined as the carbon concentration in the water passed through a $0.45-\mu \mathrm{m}$ pore size filter, and analyzed by a TOC analyzer (Apollo 9000 carbon analyzer; Teledyne-Tekmar, Cincinnati, OH). The obtained DOC level was $\sim 50 \%$ of the Suwannee River NOM. The surface zeta potential was measured using a streaming potential analyzer (SurPass Elektrokinetic Analyzer, CT, USA) after equilibration with the $\mathrm{NaCl}$ solutions. The zeta potential of the catalytic coated glass samples was calculated from the streaming potentials using the Helmholtz-Smoluchowski equation with the Fairbrother and Mastin substitution [24]. Streaming potential of the TiON film was measured as a function of $\mathrm{pH}$ in a $1 \mathrm{mM} \mathrm{NaCl}$ solution.

2.8. X-ray photoelectron spectroscopy (XPS) surface analysis of sol-gel $\mathrm{N}$-doped $\mathrm{TiO}_{2}$ coatings exposed to NOM

XPS analysis was carried out using a Thetaprobe instrument (Thermo Fisher, East Grinstead, UK). Each sample was analyzed using Al K $\alpha$ X-rays $(\mathrm{h} v=1486.6 \mathrm{eV})$ at a power of $140 \mathrm{~W}$ with 
a spot size of $400 \mu \mathrm{m}$, the analyzer being operated in constant energy mode at a pass energy of $300 \mathrm{eV}$ for the survey spectra and 20 to $50 \mathrm{eV}$ for the high-resolution spectra $(\mathrm{C} 1 \mathrm{~s}, \mathrm{O} 1 \mathrm{~s}, \mathrm{~N} 1 \mathrm{~s}$, Ti2p, Ca2p, P2p and Si2p). When necessary, and to record traces levels, the pass energy was

increased to $200 \mathrm{eV}$. The pressure in the analytical chamber was on the order of $10^{-7}$ mbar during the analysis as charge compensation using argon bleeding within the chamber was used. Quantitative surface analyses were calculated from peak areas, using the appropriate instrument modified sensitivity factors and the manufacturer's AVANTAGE software v4.84.

\section{Results and discussion}

\subsection{Direct photolysis of CBZ under UV radiation and solar simulator}

Most of the solar UV radiation reaching the earth's surface is UVA ( $99 \%)$, since the ozone layer of the atmosphere absorbs the UVC and most of the UVB. Emission spectra of the 150-W Xenon solar simulator and 0.45-kW MP UV lamp, and the molar (decadic) absorption coefficient of CBZ in water at an initial $\mathrm{CBZ}$ concentration of $1 \mathrm{mg} / \mathrm{L}$ and $\mathrm{pH} 7$, are shown in Fig. 2. CBZ absorbs light within the UVC and UVB range.

Fig. 2

CBZ has been detected in wastewater [25-27], surface water [28-30], and groundwater [31, 32]. The compound has shown little degradation or retention during bank filtration $[33,34]$ or in sediment-transport studies [32]. CBZ has been used as a marker for groundwater contamination 
through sewer exfiltration by several research groups [31,35], and was therefore selected for this study.

Direct photodegradation of CBZ after $1 \mathrm{~h}$ exposure under the solar simulator was negligible (2\%). However, under the MP UV lamp, CBZ underwent almost complete degradation after 60 min of irradiation (95\%) (data not shown). This result was expected as CBZ's maximum absorbance is at $286 \mathrm{~nm}$, which overlaps with the MP UV lamp output (Fig. 2). Doll and Frimmel [36] investigated the photodegradation of CBZ and other pollutants by simulated solar UV light and found $50 \%$ degradation of CBZ after $\sim 15 \mathrm{~h}$ with a 1000-W Xe short-arc lamp (intensities of this solar UV simulator in the UV range are 1.9 times higher than those of natural sunlight). Matamoros et al. [37] found a half life of $38.5 \mathrm{~h}$ for CBZ in DI water. Indirect photolysis of $\mathrm{CBZ}$ under $\mathrm{UV} / \mathrm{H}_{2} \mathrm{O}_{2}$ showed that $\mathrm{CBZ}$ is susceptible to degradation via hydroxyl radical-induced reactions (data not shown), making it a good candidate for photocatalytic degradation.

\subsection{Sol-gel TiON deposition}

"Sol-gel" describes a broad class of processes in which a solid phase is formed through gelation of a colloidal suspension. TiON sol-gel coatings were prepared by hydrolysis of Tialkoxide in alcohol solutions containing $\mathrm{N}$ compounds. $\mathrm{N}$-doped $\mathrm{TiO}_{2}$ coatings were deposited on commercial microscope glass slides as substrates, and the coating efficiency was determined according to CBZ removal. The samples were studied by XPS, and the N1s spectra acquired with higher resolution and count rate are reported (Fig. 3). Despite the long acquisition time, the low signal-to-noise ratio indicated a very small $\mathrm{N}$ concentration, with a value of about $0.5 \%$ obtained 
by calculating the area under the XPS peaks (annealing in air). Another interesting result was the measured binding energy of the peak observed in the recorded spectra, which was about $400 \mathrm{eV}$ : which has been attributed to interstitial doping [38].

Fig. 3

Fabricated photocatalytic materials may have an advantage over powdered photocatalytic materials suspended in water. Conventional use of the latter requires homogeneous mixing of the powder in a batch or completely mixed system, separation after use, and an understanding of the impact of particle light scattering on photon distribution in the reactor.

\subsection{Adsorption of CBZ}

Use of thin film coatings (as opposed to powders) should result in lower adsorption of molecules in the water to the catalytic surface due to lower surface area. Consequently, sorption of the catalyst to target pollutant molecules should be examined. CBZ, however, is a relatively polar, neutrally charged pharmaceutical that lacks sites for specific interactions with soils and sediments, leading to its non-appreciable sorption properties [20, 32, 39]. CBZ is not expected to adsorb to the catalyst surface by charge-attraction forces. Indeed, the surface was exposed to a solution of CBZ and, after $24 \mathrm{~h}$ of equilibrium, no sorption of CBZ was found. Moreover, no CBZ was found on the surface by XPS and ToF-SIMS (section 3.7.1) 


\subsection{Contact angle-wettability}

The hydrophilicity of the sol-gel $\mathrm{N}$-doped $\mathrm{TiO}_{2}$-coated surfaces was measured via captive air bubble method, in which the surface is immersed in DI water and air bubbles are introduced into the chamber by pressure. The value of the air bubble contact angle of the coated surface in water was $36.9 \pm 7.6^{\circ}$, and $\sim 43^{\circ}$ on non-coated glass. Birdi et al. [40] reported a similar water contact angle of $41^{\circ}$ on a glass surface. The contact angle for the $\mathrm{N}$-doped catalytic surface suggests that it is relatively highly hydrophilic and can also explain the low adsorption of the organic molecule to the catalyst.

\subsection{Streaming potential}

The ionization state of the photocatalyst surface can also be protonated and deprotonated under acidic and alkaline conditions, respectively. At the point of zero charge (Pzc), the total negative and positive charge of the catalyst is zero. The Pzc of $\mathrm{TiO}_{2}$ (Degussa P25) has been widely investigated and reported at $\mathrm{pH} 6.25$ [41]. Under acidic conditions, the positive charge of the $\mathrm{TiO}_{2}$ surface increases as the $\mathrm{pH}$ decreases; the negative charge of the $\mathrm{TiO}_{2}$ surface increases with increasing $\mathrm{pH}$. The $\mathrm{pH}$ of the solution affects the formation of hydroxyl radicals via the reaction between hydroxide ions and photoinduced holes on the $\mathrm{TiO}_{2}$ surface.

Fig. 4 illustrates the streaming potential of the sol-gel $\mathrm{N}$-doped $\mathrm{TiO}_{2}$ films as a function of $\mathrm{pH}$ in a $1 \mathrm{mM} \mathrm{NaCl}$ solution. The streaming potential was negative at all $\mathrm{pH}$ values from 4 to 10 and 
decreased with increasing $\mathrm{pH}$, indicating that the films are negatively charged at $\mathrm{pH}>4$ with an increase in negative charge at higher $\mathrm{pH}$ values, reaching a plateau at about $\mathrm{pH} 9$.

Fig. 4

\subsection{Influence of pH on photocatalysis}

The photocatalytic activity of sol-gel $\mathrm{N}$-doped $\mathrm{TiO}_{2}$ coatings was tested at different $\mathrm{pH}$ values $(5,7,8,9)$ adjusted by $10 \mathrm{mM}$ phosphate buffer saline (PBS) in water spiked with $1 \mathrm{mg} / \mathrm{L}$ CBZ. CBZ is a neutral molecule at a broad range of $\mathrm{pH}$ values, and therefore photocatalysis is affected by $\mathrm{pH}$ via the surface charge of the photocatalyst. Vogna et al. [42] investigated the $\mathrm{AOP}$ of $\mathrm{CBZ}$ with $\mathrm{UV} / \mathrm{H}_{2} \mathrm{O}_{2}$ and found that $\mathrm{CBZ}$ degradation by radical-induced reaction is not affected by changing the $\mathrm{pH}$ of the solution in the range of 2.0 to 8.0. As already noted, the ionization state of the surface of the photocatalyst can be protonated and deprotonated under acidic and alkaline conditions, respectively.

The positive holes are considered the major oxidation species at low $\mathrm{pH}$, whereas hydroxyl radicals are considered the predominant species at neutral or high $\mathrm{pH}[43,44]$. The generation of $\mathrm{OH} \bullet$ is expected to be higher due to the presence of more available hydroxyl ions on the catalyst surface. Thus, the degradation efficiency of the process is expected to be enhanced at high $\mathrm{pH}$ and Fig. 5, illustrating the removal of $\mathrm{CBZ}$ at different $\mathrm{pH}$ values, verifies this assumption. Obviously, photocatalysis increases with increasing $\mathrm{pH}$ up to $\mathrm{pH} 8$ and at $\mathrm{pH} \geq 8$, the trend is moderated. This result is in good agreement with the data obtained from the streaming potential 
measurements of the photocatalyst surface and seems to be promising since surface water tends to be basic.

Fig. 5

\subsection{Catalyst efficiency in various water types}

The chemical composition of natural waters has a substantial impact on reaction pathways due to the presence of scavenging, inhibiting and promoting compounds and their interaction with reactive species generated in the photocatalytic process. For example, Selvam et al. [45] reported a beneficial effect of transition metal ions on the degradation of 4-flurophenol following the order: $\mathrm{Mg}^{2+}>\mathrm{Fe}^{3+}>\mathrm{Fe}^{2+}>\mathrm{Cu}^{2+}$, and an inhibitory effect of inorganic anions on the degradation of 4-flurophenol following the order: $\mathrm{CO}_{3}{ }^{2-}>\mathrm{HCO}_{3}{ }^{-}>\mathrm{Cl}^{-}>\mathrm{NO}_{3}{ }^{-}>\mathrm{SO}_{4}{ }^{2-}$. Initial experiments were conducted to simulate two prominent interfering substances in the water that might have an effect on photocatalysis: NOM and calcium carbonate.

NOM is a complex mixture of different organic chemicals originating from natural biological activity in water. NOM can impact AOP efficiency via several mechanisms: light absorption, its activity as a radical inhibitor or promoter, depending on its functional groups and molecular size (as an inhibitor, $\mathrm{NOM}$ reacts with $\mathrm{OH} \bullet$ radicals to form a nonreactive species, thus terminating the chain reaction, and as a promoter, $\mathrm{NOM}$ reacts with $\mathrm{OH} \bullet$ radicals to form reactive species and secondary carbon-centered radicals [46], thus promoting the chain process), its potential adsorption to the catalyst surface, and its important role in sunlight-induced photochemical processes in surface waters. 
Matamoros et al. [37] studied the photodegradation of CBZ and other compounds in fresh water and seawater and found that it increased in river waters; they linked this phenomenon to the high DOC content in the river water, which promotes indirect photodegradation by generation of photoreactants (e.g. ${ }^{1} \mathrm{O}_{2}, \mathrm{O}_{2}, \mathrm{H}_{2} \mathrm{O}_{2}, \mathrm{e}_{\mathrm{aq}}{ }^{-}$, etc.). NOM can enhance CBZ degradation via indirect slow photodegradation in photocatalytic processes. Nevertheless, NOM can serve as an inner filter for incoming photons and can act as a radical scavenger, reducing the formation of reactive oxidation species (e.g. $\mathrm{OH} \bullet$ ) and consequently reducing process efficiency.

Fig. 6 shows the influence of different DOC concentrations $(0,2,3.5,5$ and $9 \mathrm{mg} / \mathrm{L})$ on $\mathrm{CBZ}$ photocatalysis $(1 \mathrm{mg} / \mathrm{L}$ at $\mathrm{pH} 7)$. The low concentration of DOC (2 mg/L) had only a negligible effect on CBZ removal; at $5 \mathrm{mg} / \mathrm{L}$ DOC there was an approximate $20 \%$ reduction in $\mathrm{CBZ}$ removal (see Table 1). Doll and Frimmel [47] investigated the influence of NOM on photocatalytic degradation of organic compounds (e.g. CBZ) by $\mathrm{TiO}_{2}(\mathrm{P} 25)$ and showed a $40 \%$ decrease in removal rate for only $\sim 1 \mathrm{mg} / \mathrm{L}$ NOM. This difference can be explained by the high adsorption of $\mathrm{NOM}$ onto $\mathrm{TiO}_{2}(\mathrm{P} 25)$. Mixing NOM with $\mathrm{TiO}_{2}$ in the dark resulted in adsorption of $61 \%$ of the DOC onto the catalyst. Adsorption was negligible for the sol-gel N-doped coated samples.

A $5 \%$ reduction was observed in the average dose calculated by integrating the water absorbance for a $9 \mathrm{mg} / \mathrm{L} \mathrm{DOC}$ solution (data not shown). Therefore, the decrease in CBZ photocatalytic degradation rate cannot be simply a consequence of the inner filter effect of NOM; another competitive reaction inhibiting photocatalytic degradation of CBZ must be occurring, since NOM consists of electron-rich compounds capable of scavenging the holes photogenerated in the catalyst valence band. 
Fig. 6

Table 1

\subsubsection{XPS surface analysis of sol-gel $\mathrm{N}$-doped $\mathrm{TiO}_{2}$ coating exposed to $\mathrm{NOM}$}

The surface composition, determined by XPS, is given in Table 2 in percentages. The samples were as follows: control is a sample immersed in HPLC-grade water, and NOM is a solgel sample immersed in $30 \mathrm{~mL}$ HPLC-grade water with NOM at a concentration of $18 \mathrm{mg} / \mathrm{L}$. The XPS data, in general, indicated a very low amount of $\mathrm{C}$ - even less than the amount anticipated for simple adventitious surface contamination (expected level of atmospheric contamination usually due to minimization of surface energy). Therefore, the surfaces could be considered extremely clean and devoid of contaminants, in XPS terms.

\section{Table 2}

The NOM sample exhibited a higher amount of $\mathrm{C}$ than the control samples. This is characteristic of the presence of adsorbed organic species. A careful analysis of the $\mathrm{C}$ signal of the control and NOM samples is shown in Fig. 7.

Fig. 7 
The $\mathrm{C}$ signal can be decomposed into four components at different binding energies: $285 \mathrm{eV}$ (C-C, C-H), 286.4 eV (C-O, *C-O-C=O), 287.7-287.8 eV (O-C-O) and 289.1-289.4 eV (O=CO). Of interest is the second component, which showed a significant increase after treatment with NOM and irradiation. The excess amount of the second C compared to the control is consistent with the remaining NOM material. Indeed, the water used originates from the Suwannee River, which is a blackwater river and hence contains tannins. This type of molecule has functionalities consistent with the presence of $\mathrm{C}-\mathrm{O}$ and $\mathrm{C}-\mathrm{OH}$ chemistry. The time needed to eliminate the pollutant might be higher or the coverage may influence the efficiency of the photocatalytic degradation of CBZ. In addition, surface characterization using XPS and Time-of- Light Secondary Ion Mass Spectrometry (ToF-SIMS) analysis of doped surfaces showed that the catalyst surface is clean and devoid of CBZ before and after photocatalysis (data not shown).

\subsection{Alkalinity}

To examine the effect of different concentrations of alkalinity on photocatalysis, different concentrations of bicarbonate $\left(25,50,100,200\right.$ and $300 \mathrm{mg} / \mathrm{L}$ as $\left.\mathrm{CaCO}_{3}\right)$ were added to DI water

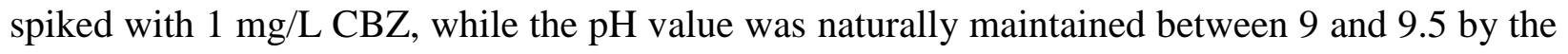
bicarbonate in the solution.

Fig. 8

Table 3 
As seen in Fig. 8, at $25 \mathrm{mg} / \mathrm{L} \mathrm{CaCO}_{3}$, there was a negligible effect of alkalinity on CBZ removal. There was a drastic decrease, however, in $\mathrm{CBZ}$ removal at $100 \mathrm{mg} / \mathrm{L} \mathrm{CaCO}_{3}$. Interestingly, after increasing the alkalinity to over $200 \mathrm{mg} / \mathrm{L} \mathrm{CaCO}_{3}$ there was a slow decrease in percent removal as compared to the initial decrease (Table 3). Carbonate alkalinity is known to inhibit photocatalysis efficiency in water by reacting with the generated $\mathrm{OH} \bullet$ radicals and forming carbonate radicals $\left(\mathrm{CO}_{3}{ }^{\circ}\right)$. Reaction rates of $\mathrm{CO}_{3}{ }^{\circ-}$ with organic compounds are usually several orders of magnitude lower than reaction rates of $\mathrm{OH} \cdot[48,49]$, and therefore their influence on CBZ removal is minor.

$\mathrm{HCO}_{3}^{-}+\mathrm{HO}^{*} \rightarrow \mathrm{H}_{2} \mathrm{O}+\mathrm{CO}_{3}^{-}$

$\mathrm{CO}_{3}^{2-}+\mathrm{HO}^{*} \rightarrow \mathrm{HO}^{-}+\mathrm{CO}_{3}^{--}$Eq. (2)

\subsection{Natural water}

The CBZ-removal efficiency of sol-gel $\mathrm{N}$-doped $\mathrm{TiO}_{2}$ surfaces was tested in groundwater, surface water from Lake Kinneret, secondary effluent wastewater, and tertiary effluent wastewater after in-line granular filtration with ferric chloride. The waters were passed through a $0.45-\mu \mathrm{m}$ filter to avoid particle effects. The water-quality parameters are displayed in Table 4. Fig. 9 illustrates the absorbance of the various waters examined and the incident irradiance of the solar simulator. There is a little overlap between the water types and the solar spectrum output.

\section{Table 4}


Fig. 9

Photocatalytic degradation of CBZ decreased drastically for all types of water with irradiation dose (Fig. 10). CBZ removal decreased from $70 \%$ in buffered water to approximately $35 \%, 21 \%$ and negligible removal with surface water, groundwater and either secondary or tertiary effluent, respectively (Table 5). Apparently, CBZ removal in groundwater is lower than in surface water due to higher alkalinity values in groundwater. The reduction in average dose integrated with the water absorbance compared to RO water was $2.6 \%$ and $5.8 \%$ for surface water and secondary effluent, respectively (data not shown). The inner filter effect of NOM can be neglected in this case as well. Secondary wastewater effluents have the highest DOC value (11 mg/L, with an alkalinity of $240 \mathrm{mg} / \mathrm{L})$, and therefore a substantial decrease in CBZ removal rate is expected. Since numerous effects can influence CBZ removal in natural waters, it is difficult to isolate which parameters influence the photocatalytic processes separately or in synergy. Although it is obvious that $\mathrm{pH}$, organic matter and alkalinity impact photocatalysis rate, other parameters not examined herein, such as metals and natural particles, might also impact adsorption to the surface and photocatalysis rate.

Fig. 10

Table 5

Only a few full-scale developments have been reported for photocatalysis in water treatment. There might be a need to improve the ratio between the catalyst's surface area and water volume 
to achieve enhanced removal with the photocatalytic surface. Nevertheless, these results provide a comparative perspective on the impact of water-quality parameters on sorption to surfaces and photocatalytic activity. When considering the application of photocatalytic reactors used to treat natural waters, it is important to understand the limitations of the method's efficiency with these waters. The first outdoor engineering-scale reactor developed for water treatment was a converted parabolic-trough solar thermal energy collector in which the absorber/glazing tube combination was replaced by a simple Pyrex glass tube through which contaminated water could flow [50]; a simple modification of the parabolic trough collector was then developed and successfully operated for experiments in which the catalyst was deployed in a slurry. Since that time, research all over the world has advanced a number of reactor concepts and designs, including concentrating and nonconcentrating reactors and other creative designs. The catalyst can be deployed in several ways - as a fixed catalyst, slurry, or neutral-density large particles. For example, [11] Miranda-Garcia et al. (2011) reported photocatalytic degradation of 15 emerging contaminants in municipal WWTP effluents using $\mathrm{TiO}_{2}$ immobilized on glass spheres.

\section{Conclusions}

1. CBZ was stable to photodegradation under direct solar irradiation.

2. Polycrystalline $\mathrm{N}$-doped $\mathrm{TiO}_{2}$ thin films have been deposited by sol-gel dip-coating

3. No sorption of CBZ to the N-doped $\mathrm{TiO}_{2}$ catalyst surface was observed, as confirmed by surface characterization using XPS analysis.

4. An excess amount of $\mathrm{C}$ was detected compared to the control when the catalyst surface was immersed in NOM, indicating some sorption of organics to the surface. 
5. The catalyst surface charge was negative at all $\mathrm{pH}$ values from 4 to 10 and the charge decreased with increasing $\mathrm{pH}$.

6. $\mathrm{CBZ}$ removal improved with increasing medium $\mathrm{pH}$ in the range of 5 to 9 .

7. DOC at a concentration of $5 \mathrm{mg} / \mathrm{L}$ resulted in an $\sim 20 \%$ reduction in CBZ removal, probably due to competitive inhibition of the photocatalytic degradation of CBZ.

8. Alkalinity values of $100 \mathrm{mg} / \mathrm{L}$ as $\mathrm{CaCO}_{3}$ resulted in an over $40 \%$ decrease in $\mathrm{CBZ}$ removal.

9. A 35\% reduction in CBZ removal occurred in the presence of surface water compared to complete suppression of the photocatalytic process in wastewater effluent.

\section{Acknowledgments}

This research is part of an international EU FP7 project entitled: Nano-structured TiON photo-catalytic membranes for water treatment (NATIOMEM). The authors would like to acknowledge Dr. Rossana Grilli and Dr. Steve Hinder from surface analysis laboratory, Surrey University, UK, for their assistance in XPS analysis, and Dr. Moshe Herzberg and Adi Avni from the Ben Gurion University of the Negev, Israel, for their assistance in streaming potential and contact angle analysis. In addition the authors would like to thank Mrs. Daniela Di Camillo for her contribution to sample coating.

\section{Figure Captions}

Figure 1: Comparison of spectra obtained from the solar simulator and natural sunlight

Figure 2: Emission spectra of the 0.45-kW MP UV lamp, 150-W Xe solar simulator and extinction coefficient of CBZ in DI water at an initial CBZ concentration of $1 \mathrm{mg} / \mathrm{L}$ and $\mathrm{pH} 7$. 
Figure 3: XPS survey spectra of sol-gel N-doped $\mathrm{TiO}_{2}$ samples after annealing in air.

Figure 4: Streaming potential (ZP) of sol-gel N-doped $\mathrm{TiO}_{2}$ surface vs. $\mathrm{pH}$ in a $1 \mathrm{mM} \mathrm{NaCl}$ solution.

Figure 5: CBZ removal as a function of medium $\mathrm{pH}$

Figure 6: Percent CBZ removal as a function of different DOC concentrations of NOM.

Figure 7: Comparison of XPS C1s signal for control (left) and NOM sample (right).

Figure 8: Percent CBZ removal as a function of different alkalinities (as $\mathrm{CaCO} 3$ concentration).

Figure 9: Emission spectra of the solar Xe lamp and absorbance spectra of the tested waters.

Figure 10: Percent CBZ removal in different water sources

Table 1: Percent CBZ removal with different DOC concentrations after 90 min of exposure.

Table 2: Comparison of surface composition in all batches (at \%).

Table 3: Percent CBZ removal with different levels of alkalinity (CaCO3 concentrations), after 90 min of irradiation.

Table 4: Water-quality analysis for different water sources.

Table 5: Percent CBZ removal for different water types after 90 min of irradiation.

\section{References}

[1] Sullivan PJ, Agardy FJ, Clark JJJ. The environmental science of drinking water. 1st ed. Burlington, MA: Elsevier Butterworth-Heinemann; 2005.

[2] Avisar D, Lester Y, Ronen D. Sulfamethoxazole detected in a deep phreatic aquifer beneath effluent irrigated land. Sci Total Environ 2009a;407:4278-82. 
[3] Avisar D, Levin G, Gozlan I. The processes affecting oxytetracycline contamination of groundwater in a phreatic aquifer underlying industrial fish ponds in Israel. Environ Earth Sci 2009b;59:939-45.

[4] Ollers S, Singer HP, Fassler P, Muller SR. Simultaneous quantification of neutral and acidic pharmaceuticals and pesticides at the low-ng/l level in surface and waste water. J Chromatog A 2001;911:225-34.

[5] Rizzo L, Meric S, Guida M, Kassinos D, Belgiorno V. Heterogeneous photocatalytic degradation kinetics and detoxification of an urban wastewater treatment plant effluent contaminated with pharmaceuticals. Water Res 2009;43:4070-8.

[6] Hoffmann MR, Martin ST, Choi WY, Bahnemann DW. Environmental applications of semiconductor photocatalysis. Chem Rev 1995;95:69-96.

[7] Doll TE, Frimmel FH. Removal of selected persistent organic pollutants by heterogeneous photocatalysis in water. Catalysis Today 2005a;101:195-202.

[8] Reyes C, Fernandez J, Freer J, Mondaca MA, Zaror C, Malato S, Mansilla HD. Degradation and inactivation of tetracycline by $\mathrm{TiO} 2$ photocatalysis. J Photochem Photobiol A Chem 2006;184:141-6.

[9] Yang L, Yu LE, Ray MB. Degradation of paracetamol in aqueous solutions by TiO2 photocatalysis. Water Res 2008;42:3480-8.

[10] Hapeshi E, Achilleos A, Vasquez MI, Michael C, Xekoukoulotakis NP, Mantzavinos D, Kassinos D. Drugs degrading photocatalytically: Kinetics and mechanisms of ofloxacin and atenolol removal on titania suspensions. Water Res 2010;44:1737-46.

[11] Miranda-Garcia N, Suarez S, Sanchez B, Coronado B, Malato S, Maldonado MI. Photocatalytic degradation of emerging contaminants in municipal wastewater treatment 
plant effluents using immobilized $\mathrm{TiO} 2$ in a solar pilot plant. Appl Catalysis B Environ 2011;103:294-301.

[12] Rincon AG, Pulgarin C. Bactericidal action of illuminated $\mathrm{TiO} 2$ on pure Escherichia coli and natural bacterial consortia: Post-irradiation events in the dark and assessment of the effective disinfection time. Appl Catalysis B Environ 2004;49:99-112.

[13] Sjogren JC, Sierka RA. Inactivation of phage MS2 by iron-aided titanium-dioxide photocatalysis. Appl Environ Microbiol 1994;60:344-7.

[14] Carp O, Huisman CL, Reller A. Photoinduced reactivity of titanium dioxide. Progr Solid State Chem 2004;32:33-177.

[15] Wong CL, Tan YN, Mohamed AR. A review on the formation of titania nanotube photocatalysts by hydrothermal treatment. J Environ Manage 2011;92:1669-80.

[16] Lin CF, Wu CH, Onn ZN. Degradation of 4-chlorophenol in TiO2, WO3, SnO2, TiO2/WO3 and $\mathrm{TiO} 2 / \mathrm{SnO} 2$ systems. J Hazard Materials 2008;154:1033-9.

[17] Martinez C, Canle M, Fernandez MI, Santaballa JA, Faria J. Kinetics and mechanism of aqueous degradation of carbamazepine by heterogeneous photocatalysis using nanocrystalline $\mathrm{TiO} 2, \mathrm{ZnO}$ and multi-walled carbon nanotubes-anatase composites. Appl Catalysis B Environ 2011;102:563-71.

[18] Asahi R, Morikawa T, Ohwaki T, Aoki K, Taga Y. Visible-light photocatalysis in nitrogendoped titanium oxides. Science 2001;293:269-71.

[19] Joss A, Zabaczynski S, Göbel A, Hoffmann B, Löffler D, McArdell CS, Ternes TA, Thomsen A, Siegrist H. Biological degradation of pharmaceuticals in municipal wastewater treatment: Proposing a classification scheme. Water Res 2006;40:1686-96. 
[20] Clara M, Strenn B, Kreuzinger N. Carbamazepine as a possible anthropogenic marker in the aquatic environment: Investigations on the behaviour of carbamazepine in wastewater treatment and during groundwater infiltration. Water Res 2004;38:947-54.

[21] Kosjek T, Andersen HR, Kompare B, Ledin A, Heath E. Fate of carbamazepine during water treatment. Environ Sci Technol 2009;43:6256-61.

[22] Yu J, Zhao X, Du J, Chen W. Preparation, microstructure and photocatalytic activity of the porous TiO2 anatase coating by sol-gel processing. J Sol-Gel Sci Technol 2000;17:163.

[23] APHA (American Public Health Association), AWWA (American Water Works Association), Water Environment Federation (WEF). Standard Methods for the Examination of Water and Wastewater, $21^{\text {st }}$ ed., (2005) Washington, D.C.,

[24] Elimelech M, Gregory J, Jia X, Williams R. Particle deposition and aggregation: measurement, modeling and simulation. Butterworth-Heinemann; 1995.

[25] Castiglioni S, Bagnati R, Fanelli R, Pomati F, Calamari D, Zuccato E. Removal of pharmaceuticals in sewage treatment plants in Italy. Environ Sci Technol 2006;40:357-63.

[26] Miao XS, Yang JJ, Metcalfe CD. Carbamazepine and its metabolites in wastewater and in biosolids in a municipal wastewater treatment plant. Environ Sci Technol 2005;39:7469-75.

[27] Reemtsma T, Weiss S, Mueller J, Petrovic M, Gonzalez S, Barcelo D, Ventura F, Knepper TP. Polar pollutants entry into the water cycle by municipal wastewater: A European perspective. Environ Sci Technol 2006;40:5451-8.

[28] Dsikowitzky L, Schwarzbauer J, Littke R. The anthropogenic contribution to the organic load of the Lippe River (Germany). Part II: Quantification of specific organic contaminants. Chemosphere 2004;57:1289-300. 
[29] Tixier C, Singer HP, Oellers S, Muller SR. Occurrence and fate of carbamazepine, clofibric acid, diclofenac, ibuprofen, ketoprofen, and naproxen in surface waters. Environ Sci Technol 2003;37:1061-8.

[30] Wiegel S, Aulinger A, Brockmeyer R, Harms H, Loffler J, Reincke H, Schmidt R, Stachel B, von Tumpling W, Wanke A. Pharmaceuticals in the river Elbe and its tributaries. Chemosphere 2004;57:107-26.

[31] Fenz R, Blaschke AP, Clara M, Kroiss H, Mascher D, Zessner M. Quantification of sewer exfiltration using the anti-epileptic drug carbamazepine as marker species for wastewater. Water Sci Technol 2005;52:209-17.

[32] Drewes JE, Heberer T, Rauch T, Reddersen K. Fate of pharmaceuticals during ground water recharge. Ground Water Monitoring Remediation 2003;23:64-72.

[32] Scheytt TJ, Mersmann P, Heberer T. Mobility of pharmaceuticals carbamazepine, diclofenac, ibuprofen, and propyphenazone in miscible-displacement experiments. J Contam Hydrol 2006;83:53-69.

[34] Heberer T, Mechlinski A, Fanck B, Knappe A, Massmann G, Pekdeger A, Fritz B. Field studies on the fate and transport of pharmaceutical residues in bank filtration. Ground Water Monitoring Remediation 2004;24:70-7.

[35] Kahle M, Buerge IJ, Muller MD, Poiger T. Hydrophilic anthropogenic markers for quantification of wastewater contamination in ground- and surface waters. Environ Toxicol Chem 2009;28:2528-36.

[36] Doll TE, Frimmel FH. Fate of pharmaceuticals - Photodegradation by simulated solar UVlight. Chemosphere 2003;52:1757-69. 
[37] Matamoros V, Duhc A, Albaiges J, Bayona J. Photodegradation of carbamazepine, ibuprofen, ketoprofen and 17 -ethinylestradiol in fresh and seawater. Water Air Soil Pollut 2009;196:161-8.

[38] Lee S-H, Yamasue E, Ishihara KN, Okumura H. Photocatalysis and surface doping states of N-doped TiOx films prepared by reactive sputtering with dry air. Appl Catalysis B Environ 2010;93:217-26.

[39] Ternes TA, Meisenheimer M, McDowell D, Sacher F, Brauch HJ, Haist-Gulde B, Preuss G, Wilme U, Zulei- Seibert N. Removal of pharmaceuticals during drinking water treatment. Environ Sci Technol 2002;36:3855-63.

[40] Birdi K, Vu D, Winter A. A study of the evaporation rates of small water drops placed on a solid surface. J Phys Chem A 1989;93:3702-3.

[41] Zhu X, Yuan C, Bao Y, Yang J, Wu Y. Photocatalytic degradation of pesticide pyridaben on TiO2 particles. J Mol Catalysis A Chem 2005;229:95-105.

[42] Vogna D, Marotta R, Andreozzi R, Napolitano A, d'Ischia M. Kinetic and chemical assessment of the UV/H2O2 treatment of antiepileptic drug carbamazepine. Chemosphere 2004;54:497-505.

[43] Mathews RW. Photooxidation of organic material in aqueous suspensions of titanium dioxide. Water Res 1986;20:569-78.

[44] Shifu C, Gengyu C. Photocatalytic degradation of pesticides using floating photocatalyst TiO2.SiO2 beads by sunlight. Solar Energy 2005;79:1-9.

[45] Selvam K, Muruganandham M, Muthuvel I, Swaminathan M. The influence of inorganic oxidants and metal ions on semiconductor sensitized photodegradation of 4-flurophenol. Chem Eng J 2007;128:51-7. 
[46] Bianchini R, Calucci L, Lubello C, Pinzino C. Intermediate free radicals in the oxidations of wastewater. Res Chem Intermediates 2002;28:247-56.

[47] Doll TE, Frimmel FH. Photocatalytic degradation of carbamazepine, clofibric acid and iomeprol with P25 and Hombikat UV100 in the presence of natural organic matter (NOM) and other organic water constituents. Water Res 2005b;39:403-11.

[48] Bhatkhande DS, Pangarkar VG, Beenackers AA. Photocatalytic degradation for environmental applications—a review. J Chem Technol Biotechnol 2002;77:102-16.

[49] Huang JP, Mabury SA. A new method for measuring carbonate radical reactivity toward pesticides. Environ Toxicol 2000;19:1501-7.

[50] Goswami DY, Blake DM. Cleaning up with sunshine. Mech Eng 1996;118:56-9. 


\begin{tabular}{|l|l|l|l|l|l|}
\hline DOC conc. (mg/L) & $\mathbf{0}$ & $\mathbf{2}$ & $\mathbf{3 . 5}$ & $\mathbf{5}$ & $\mathbf{9}$ \\
\hline \% Removal & 70 & 68.3 & 59.6 & 53.2 & 49.5 \\
\hline
\end{tabular}

Table 1 


\begin{tabular}{|c|c|c|c|c|c|c|}
\hline Sample & $\mathrm{C}$ & $\mathrm{O}$ & $\mathrm{N}$ & $\mathrm{Ti}$ & $\mathrm{Ca}$ & $\mathrm{Si}$ \\
\hline Control 1 & 14.2 & 48.5 & 0.4 & 16.6 & - & - \\
\hline Control 2 & 15.9 & 59.3 & 0.6 & 13.3 & 0.6 & 5.8 \\
\hline NOM & 19.4 & 59.4 & 0.6 & 13.7 & 0.4 & 5.5 \\
\hline
\end{tabular}

Table 2 


\begin{tabular}{|l|l|l|l|l|l|l|}
\hline Alk conc. (mg/L as $\mathrm{CaCO}_{3}$ ) & $\mathbf{0}$ & $\mathbf{2 5}$ & $\mathbf{5 0}$ & $\mathbf{1 0 0}$ & $\mathbf{2 0 0}$ & $\mathbf{3 0 0}$ \\
\hline \% Removal & 72.6 & 68.5 & 60.6 & 42.4 & 36.8 & 30.3 \\
\hline
\end{tabular}

Table 3 


\begin{tabular}{|l|c|c|c|c|c|c|}
\hline \multirow{2}{*}{ Water type } & \multicolumn{5}{|c|}{ Water quality parameter } \\
\cline { 2 - 7 } & $\mathbf{p H}$ & $\begin{array}{c}\mathbf{D O C} \\
(\mathbf{m g} / \mathbf{L})\end{array}$ & $\begin{array}{c}\text { Alkalinity } \\
(\mathbf{m g} / \mathbf{L} \text { as } \\
\mathbf{C a C O})\end{array}$ & $\begin{array}{c}\text { Total } \\
\text { hardness } \\
(\mathbf{m g} / \mathbf{L} \text { as } \\
\mathbf{C a C O})\end{array}$ & $\begin{array}{c}\text { Chlorides } \\
(\mathbf{m g} / \mathbf{L} \mathbf{C l})\end{array}$ & $\begin{array}{c}\text { Turbidity } \\
(\mathbf{N T U})\end{array}$ \\
\hline Groundwater & 8.1 & - & 224 & 270 & 80 & - \\
\hline Surface water & 8.2 & 3 & 114 & 260 & 288 & 0.5 \\
\hline $\begin{array}{l}\text { Secondary } \\
\text { effluent }\end{array}$ & 8.1 & 11 & 240 & 290 & 288 & 3.6 \\
\hline Tertiary effluent & 7.3 & 7.5 & 210 & 260 & 320 & 0.8 \\
\hline
\end{tabular}

Table 4 


\begin{tabular}{|l|c|c|c|c|}
\hline Water type & Groundwater & Surface water & $\begin{array}{l}\text { Secondary } \\
\text { effluent }\end{array}$ & $\begin{array}{l}\text { Tertiary } \\
\text { effluent }\end{array}$ \\
\hline$\%$ Removal & 21.1 & 35.3 & 3.6 & 5 \\
\hline
\end{tabular}

Table 5 


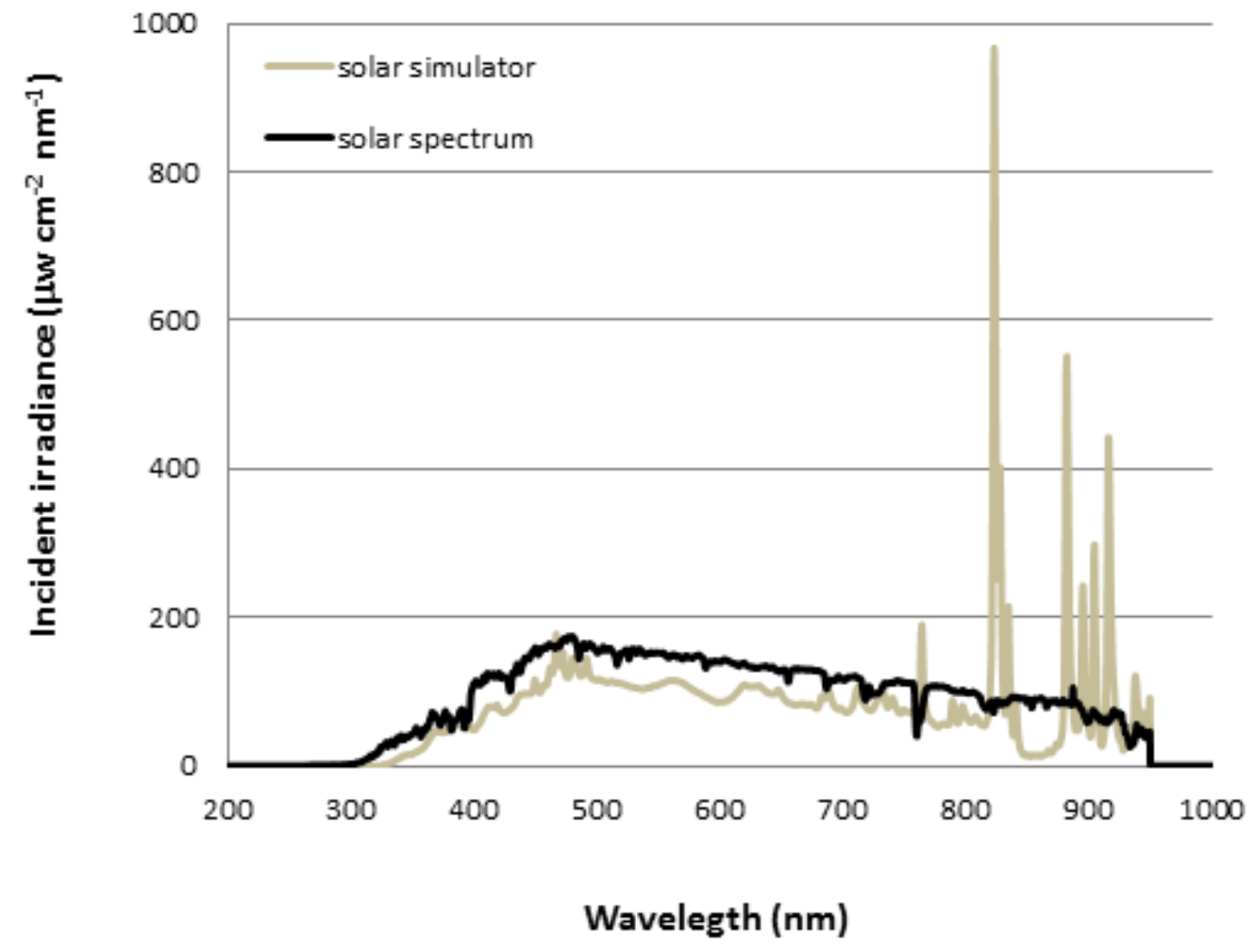

Fig 1 


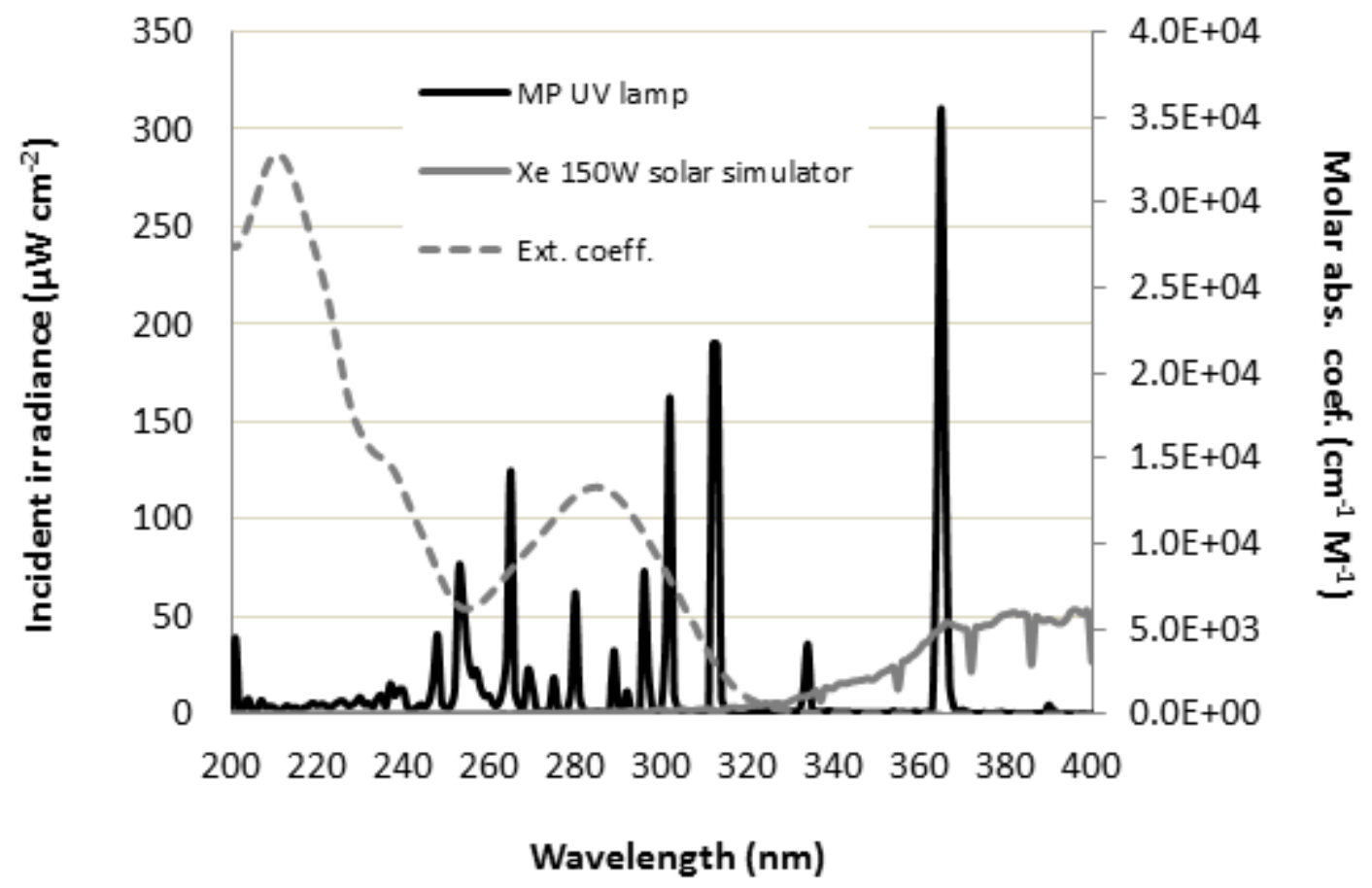

Fig 2 


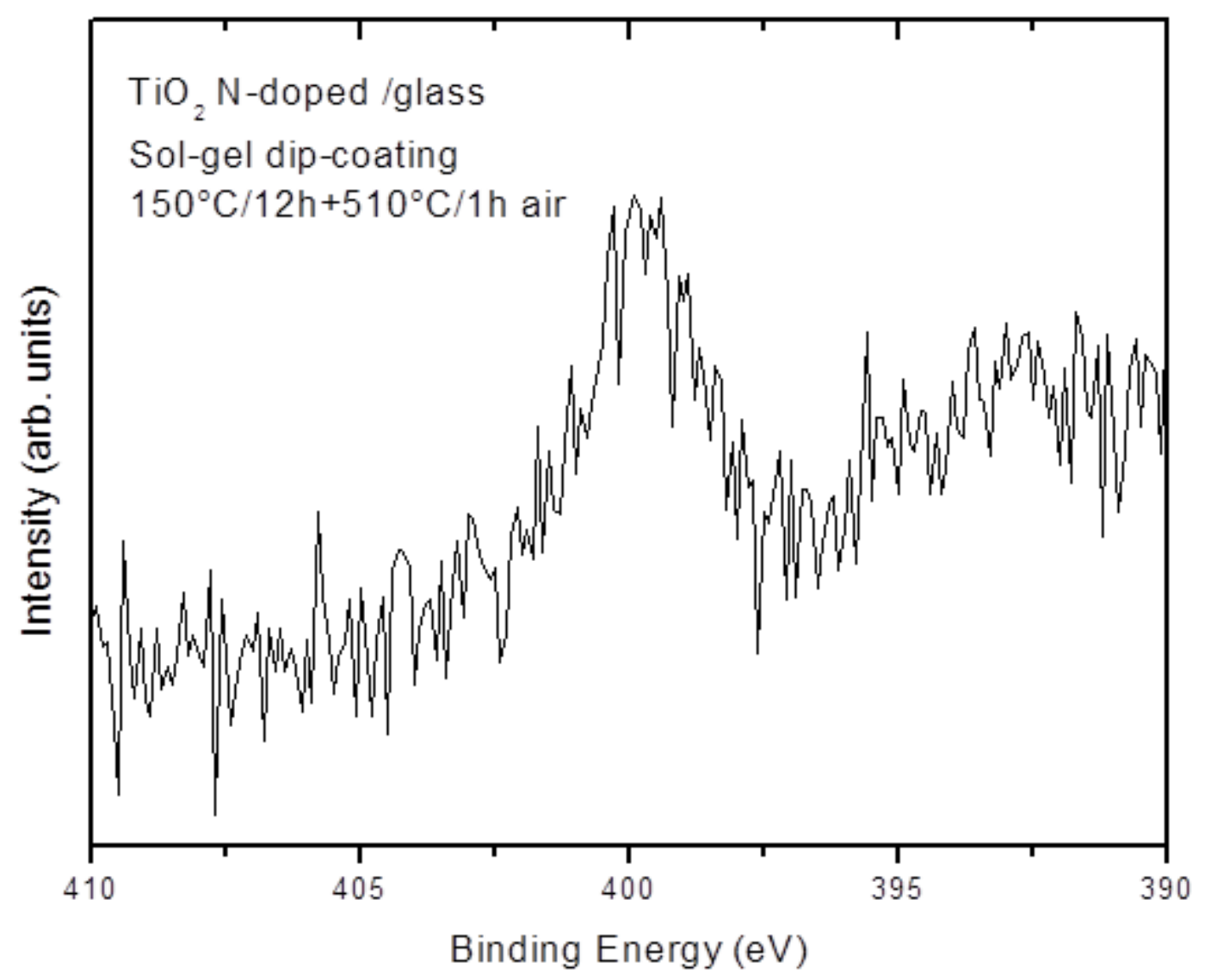

Fig 3 


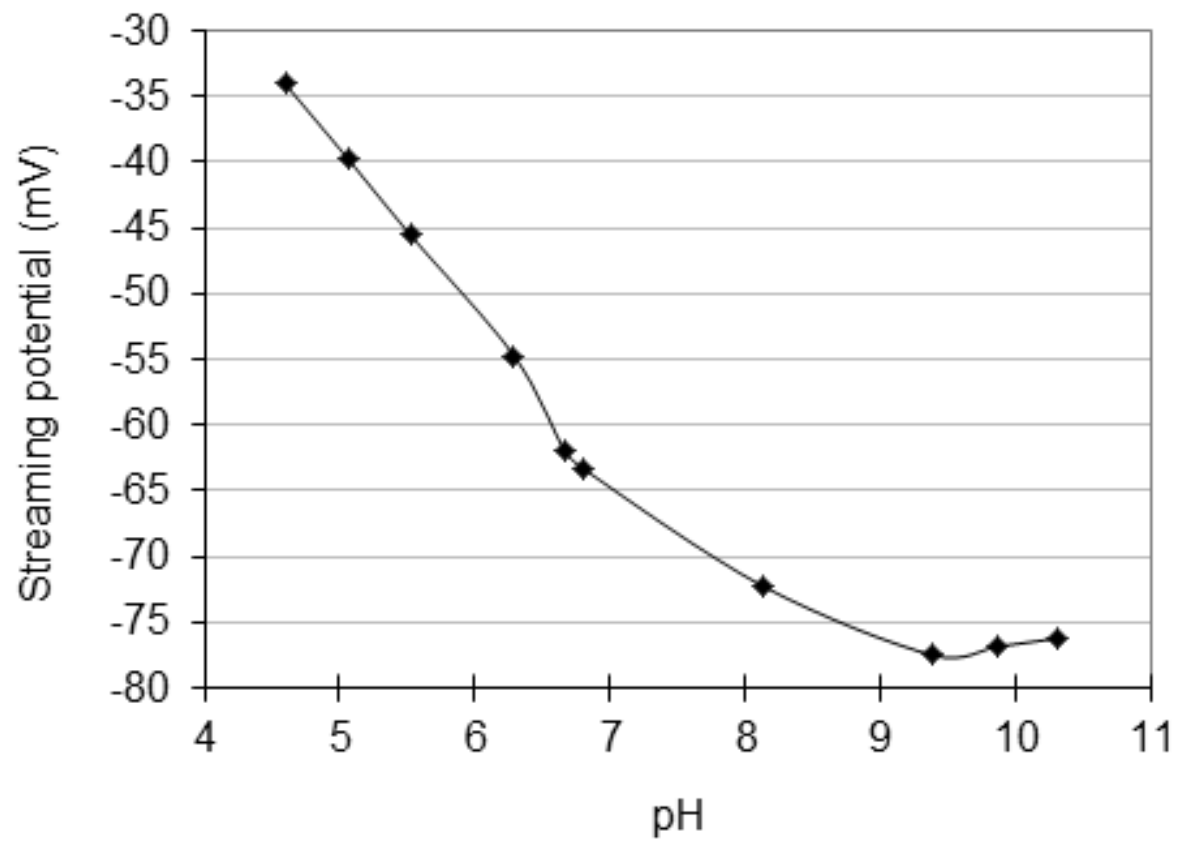

Fig 4 


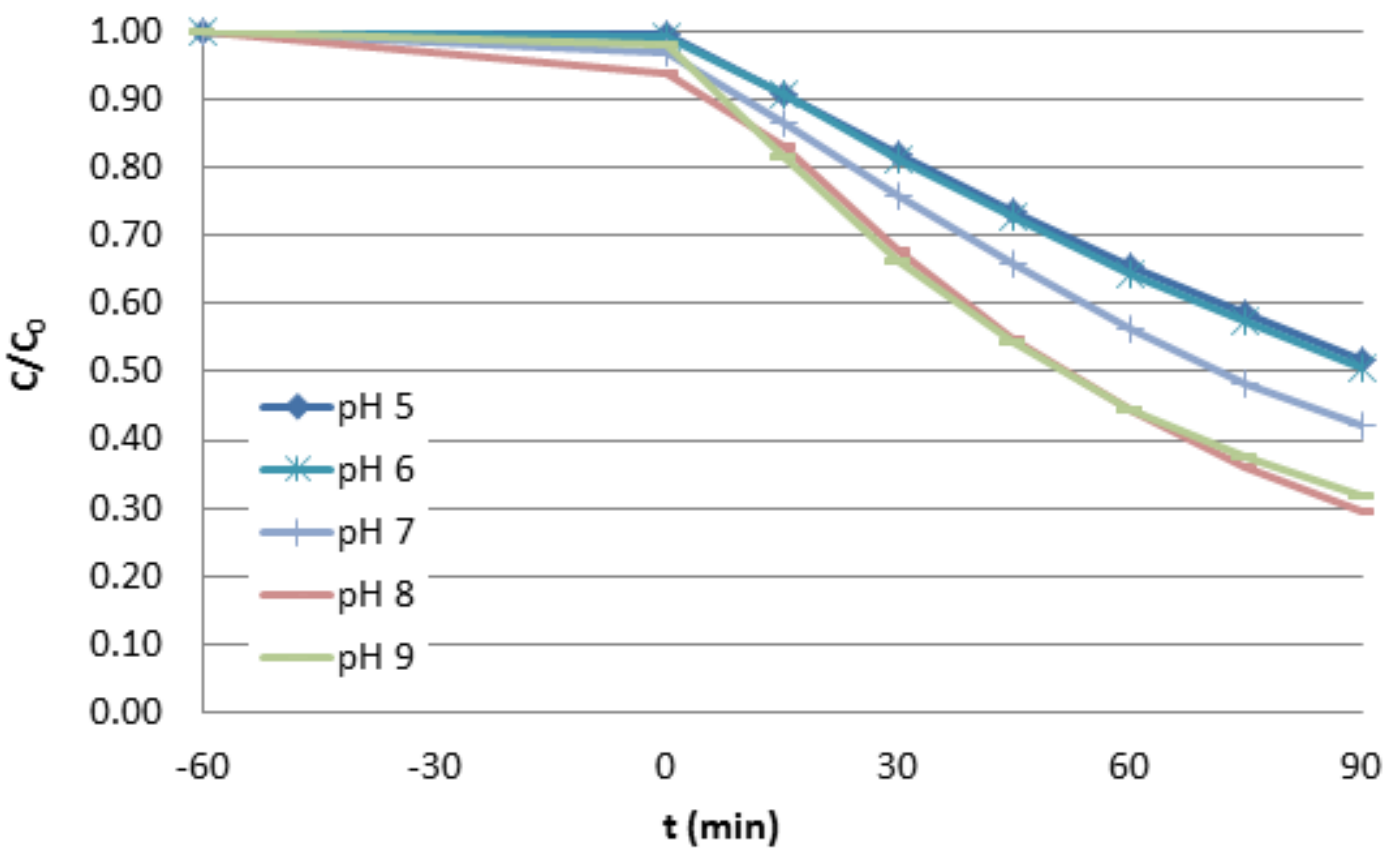

Fig 5 


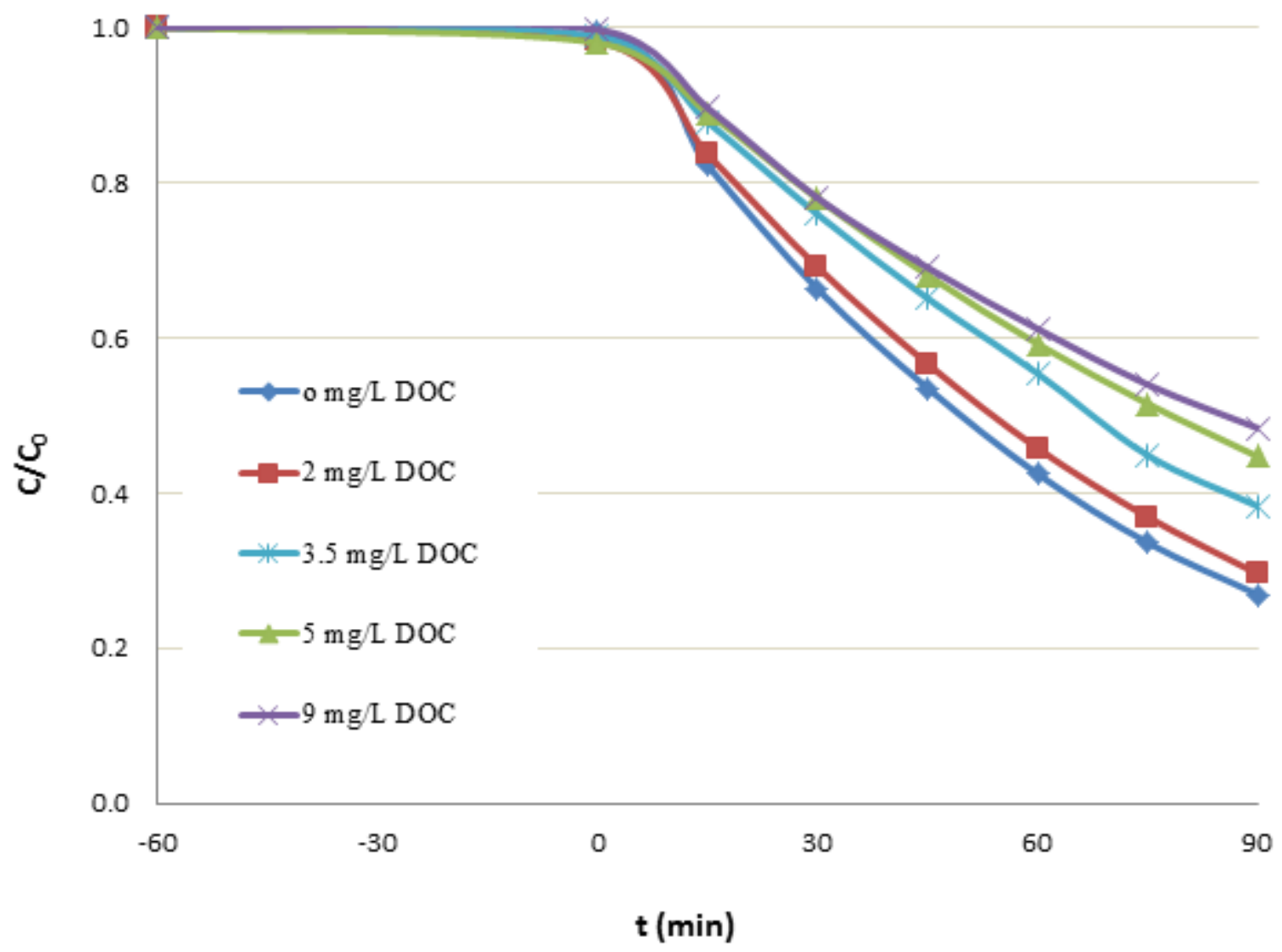

Fig 6 

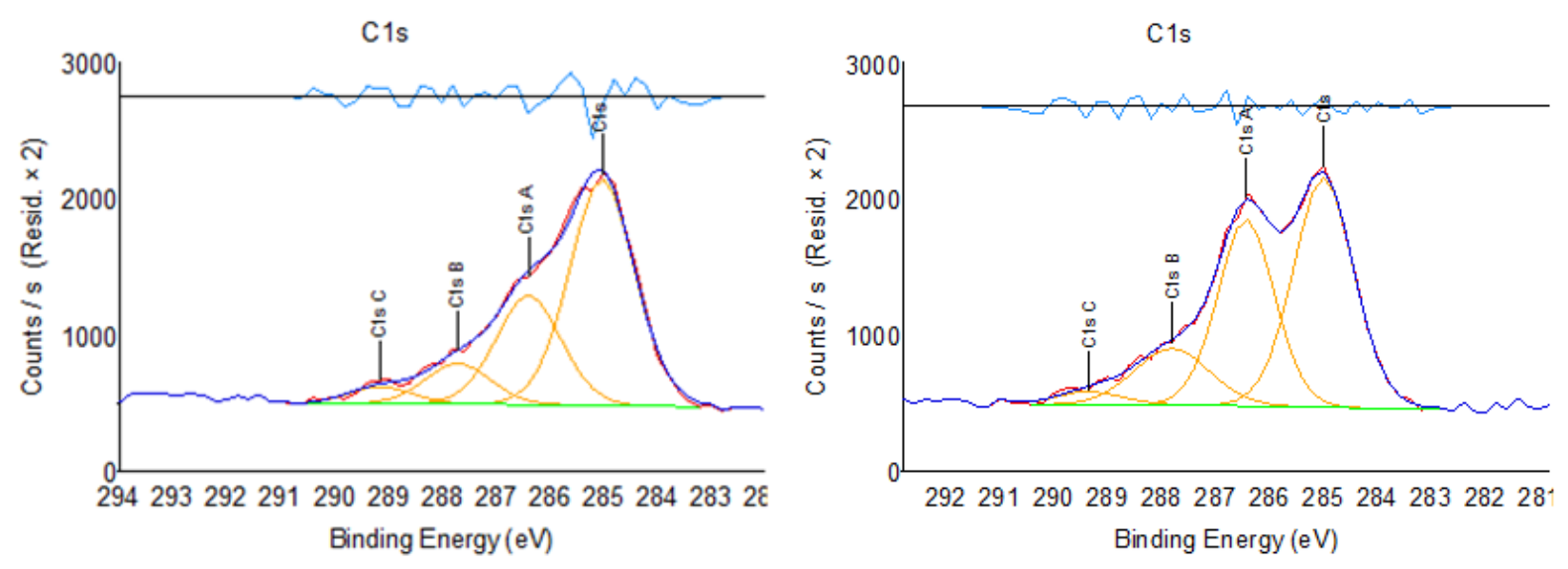

Fig 7 


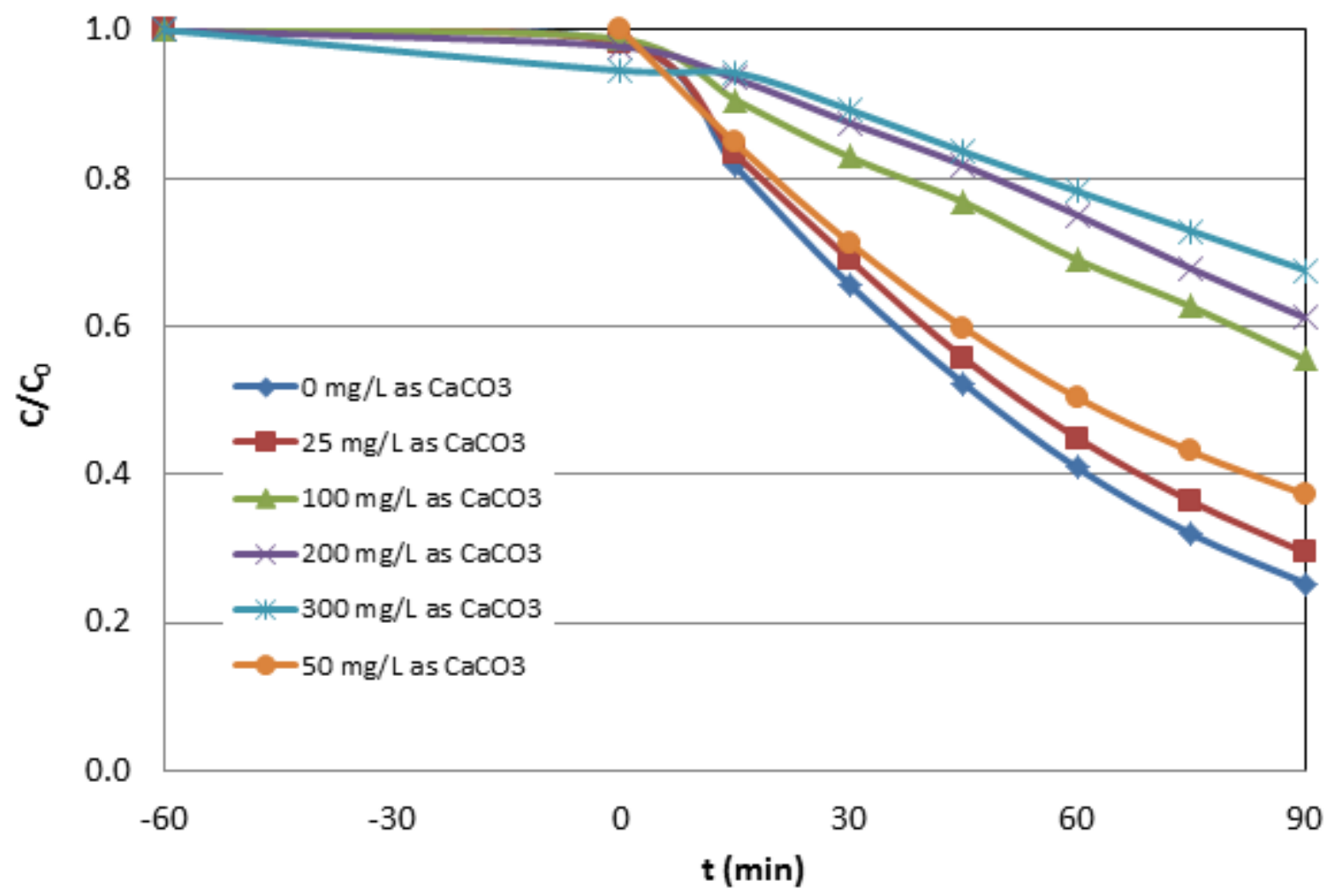

Fig 8 


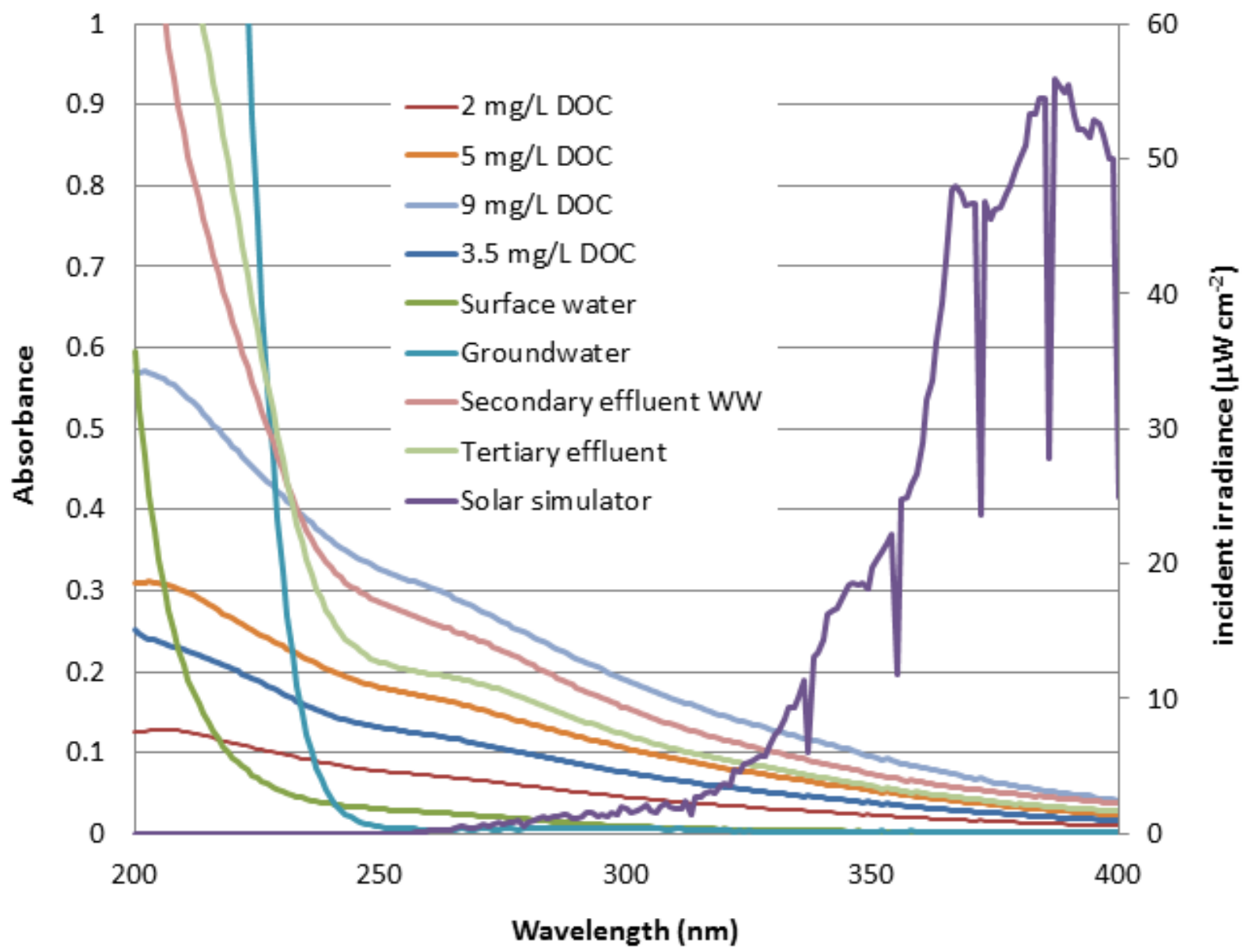

Fig 9 


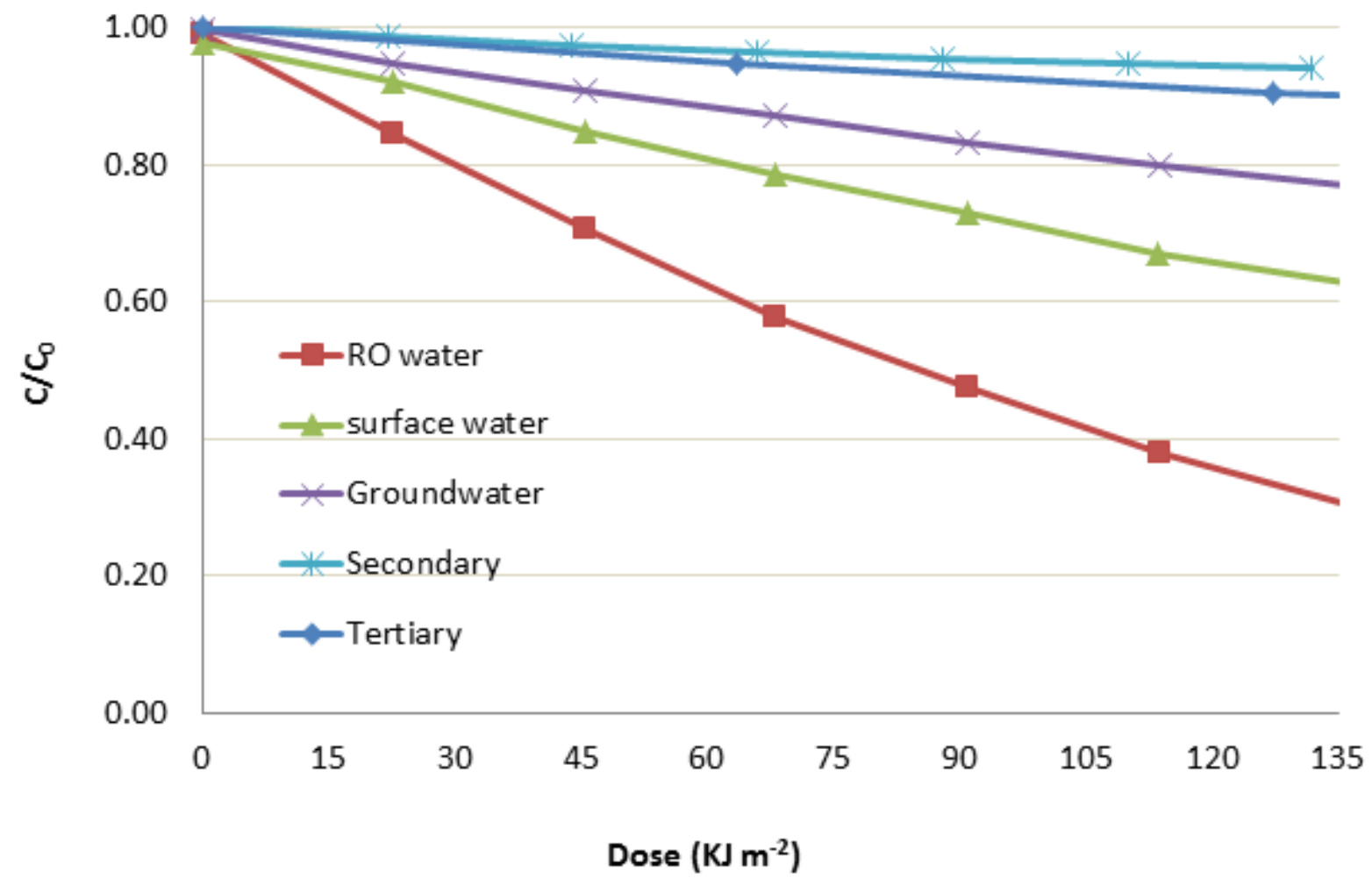

Fig 10 